\title{
Obituary
}

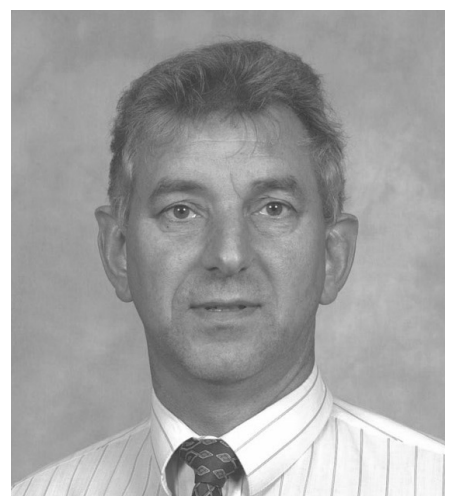

\section{Thomas Acamovic LRSC, MRSC, PhD, FRSC 1952-2009}

Tom Acamovic was born on 17 February 1952 in Edinburgh. His passing deprives the animal science community of one of its outstanding individuals. A scientist respected by nutritionists in academia and the commercial sector alike. A scientist whose legacy stretches far beyond his native Scotland.

Tom entered employment as a Scientific Officer with SAC in 1968 and immediately started to work at what were to become the two main themes of his professional life - chemistry and animal nutrition. He moved from the SAC site in Edinburgh to the Aberdeen site in 1989 to take up a position of Research Scientist and Lecturer. Over the next ten years Tom developed his interest in farmed animal nutrition and in particular the roles of anti-nutritional factors in ruminant and monogastric diets, building, in the process, an extensive network of international collaborators. In 1997 he moved to SAC's Ayr campus to take up the post of Senior Research Scientist at the SAC Avian Science Research Centre. Credited with over 260 publications, Tom was one of the UK's leading poultry nutritionists.

Tom's passion for his work was obvious to all who met him. What may have been less obvious was the strength of character that underpinned his love for his work, a strength of character which defined Tom as an individual. If he didn't understand Tom would ask, if he disagreed Tom would stand up and discuss. Where others may hold back, concerned at looking foolish or stepping out of line, Tom would step forward. In themselves these are admirable but not necessarily unusual traits. What marked Tom out was his lack of ego. He believed in a team approach to work and in developing the skills and careers of those around him. Nowhere was this more evident than in the supervision of the more than 20 postgraduate students that worked with him - students whose research and futures were as important to Tom as his own career.

Tom was diagnosed with cancer over four years ago, but it was something that the casual acquaintance could have been unaware of. He was no respecter of his illness and carried on working with the same passion and enthusiasm that had characterised him before his diagnosis.

Tom was elected as President of the UK Branch of the Worlds Poultry Science Association, in 2006. Within months of his appointment he initiated and drove the UK Branch's bid to bring the World Poultry Congress to Glasgow in 2016. At the same time he was chairing the group that was organising the 17th European Symposium on Poultry Nutrition (ESPN) which was held in August in Edinburgh. Neither event was, in Tom's mind, about Tom. They were about a team bringing together mutual friends to discuss science in what, as Tom would never tire of telling people, was the best country in the world. Sadly he did not live long enough to attend the 17 th ESPN but the success of this meeting will be one of his many legacies. 


\section{Obituary}

Another of Tom's legacies will be the application of his research. There are a handful of scientists working in institutes and universities across the world with whom the commercial sector choose to work. In this respect Tom's ability to apply his knowledge to the practical problems facing companies that manufacture feed or feed additives placed him at the forefront of his field. Working with the leading companies he has made a major contribution to the way in which poultry are, and will be, fed in the future.

Tom collaborated with scientists across the world and counted many as personal friends. Within SAC he worked at Edinburgh, Aberdeen and Ayr. All who worked with Tom will have many memories of time spent together. He will be remembered as a scientist who challenged and innovated but most of all it will be Tom the man who is missed - for his friendship, support and sense of humour. He will be remembered with great affection.

Tom remained enthusiastic about his work until the very end and did not allow his final years to be defined by his illness. But those who knew him well knew that, above all, Tom's first and main love was not his science but his family and that he took far more pride in the achievements of Fiona, Euan and Eilidh than he ever did in his own successes. We acknowledge and celebrate the contribution which he made to science, education and humanity and trust that his family will be strengthened and encouraged by the many happy memories of Tom. 